\title{
Laser Diode: A Solution for Recurring Oral Mucocele in Children
}

\author{
Siji Elizabeth ${ }^{1} \odot$, Bhavna Gupta Saraf ${ }^{2}$, Neha Sheoran ${ }^{3}$, Gauri Kalra ${ }^{4}$, Meenu Taneja ${ }^{5}$, Shweta Rehani ${ }^{6}$
}

\begin{abstract}
Oral mucocele is an asymptomatic, non-neoplastic lesion of the salivary glands caused due to mechanical trauma to the excretory ducts. With an incidence of 2.5 lesions per 1,000, it is most common among pediatric patients. Clinically, they appear as well-circumscribed, round, single or multiple, and soft and fluctuant swellings. Although various surgical and nonsurgical treatment modalities are present in the literature, diode lasers provide a simple, rapid, effective, bloodless, and well-accepted procedure for treating mucocele in pediatric patients.

Keywords: Laser diode, Mucocele, Oral lesion.

Journal of Oral Health and Community Dentistry (2021): 10.5005/jp-journals-10062-0117
\end{abstract}

\section{INTRODUCTION}

The term "mucocele" is derived from the Latin terms mucus and coele, which means mucus in the cavity. It is defined as the collection of mucus in the subepithelial tissue, secreted from the salivary glands and their ducts in the oral cavity. ${ }^{1}$ They are also found in the lacrimal sac and in the paranasal sinuses. Mucoceles are classified into extravasation mucoceles and retention mucoceles. ${ }^{2}$ Although they occur at any age, typically they occur in the second and third decades of life. Mechanical trauma to the gland's excretory duct is the primary cause. Clinically, they are distinguished by single or numerous, soft and fluctuant nodules varying in hue from normal pink to deep blue. ${ }^{3}$ Mucocele rarely resolve on their own and have a great tendency of recurrence thus requiring proper management, especially in children with behavioral problems that can be challenging at times.

\section{Case Report}

A 5-year-old male patient reported to the department with the chief complaint of recurring asymptomatic swelling in the labial mucosa of lower lips for the past one month (Fig. 1). No significant medical history or any known allergy was noted. On personal history, patient reported oral habit of lip biting frequently since 6 months. On clinical examination of the lesion, a whitish red, translucent swelling of size $5 \times 5 \mathrm{~mm}$ was noted on the inner aspect of the lower lip on the labial mucosa for the past one month, which had increased in size gradually over time and changed in color from reddish to whitish. The patient also reported having mild discomfort while eating and speaking.

\section{Management of Lesion}

The initial clinical diagnosis of the lesion was established on the basis of lesion history and clinical features. The lesion was removed under local anesthesia using a diode laser (Fig. 2) with a wavelength of $976 \mathrm{~nm}$ in continuous mode at a power setting of $2 \mathrm{~W}$. First, a topical lignocaine anesthetic gel was applied over the lesion, followed by infiltration in the periphery of the lesion using $2 \%$ lignocaine with 1:100,000 epinephrine. The fiber tip of the diode laser was initiated by moving the fiber tip across a black articulating
${ }^{1-4}$ Department of Pedodontics and Preventive Dentistry, Sudha Rustagi College of Dental Sciences and Research, Faridabad, Haryana, India ${ }^{5}$ Department of Periodontology, Sudha Rustagi College of Dental Sciences and Research, Faridabad, Haryana, India

${ }^{6}$ Department of Oral Pathology, Sudha Rustagi College of Dental Sciences and Research, Faridabad, Haryana, India

Corresponding Author: Siji Elizabeth, Department of Pedodontics and Preventive Dentistry, Sudha Rustagi College of Dental Sciences and Research, Faridabad, Haryana, India, Phone: +91 9654578760, e-mail: sijielizabethsaji@gmail.com

How to cite this article: Elizabeth S, Saraf BG, Sheoran N, et al. Laser Diode: A Solution for Recurring Oral Mucocele in Children. J Oral Health Comm Dent 2021;15(3):146-148.

Source of support: Nil

Conflict of interest: None

paper until it became a useful hot thermal contact device. Laserspecific safety eye wear was used by the patient, operator, and the assistant during the procedure. The lesion periphery, including

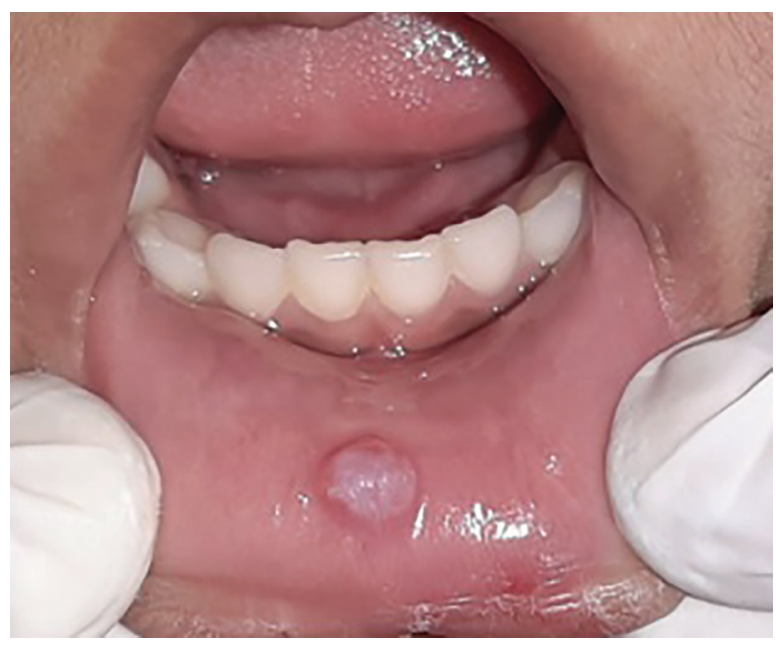

Fig. 1: Lower lip showing mucocele

(O) The Author(s). 2021 Open Access This article is distributed under the terms of the Creative Commons Attribution 4.0 International License (https://creativecommons. org/licenses/by-nc/4.0/), which permits unrestricted use, distribution, and non-commercial reproduction in any medium, provided you give appropriate credit to the original author(s) and the source, provide a link to the Creative Commons license, and indicate if changes were made. The Creative Commons Public Domain Dedication waiver (http://creativecommons.org/publicdomain/zero/1.0/) applies to the data made available in this article, unless otherwise stated. 


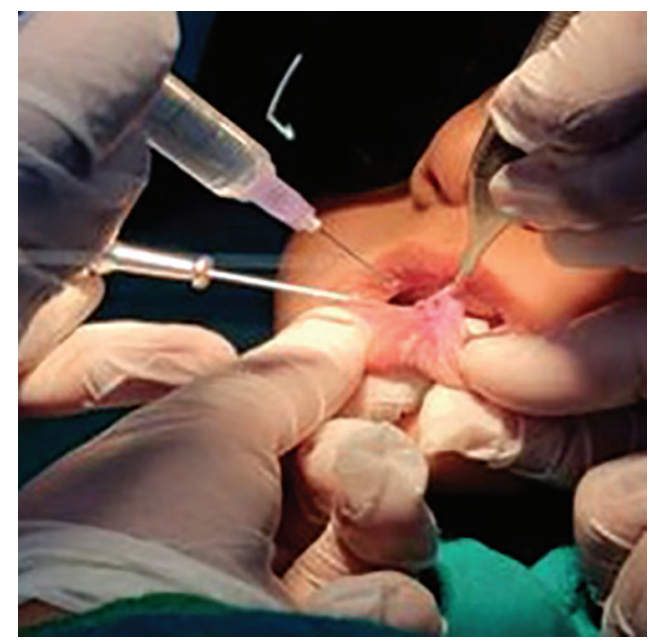

Fig. 2: Laser diode application on mucocele

an extra $1 \mathrm{~mm}$ of tissue, was marked using an eosin pencil. After initiation of the diode laser, mucocele was excised by retracting or pulling it away from the surface and simultaneously separating the lesion and its associated minor salivary gland tissue from the adjacent surface using tissue-holding forceps. A water-moistened gauze pad was used to control the temperature of the tissues with simultaneous application of a water jet on the spot using a syringe, and alternatively air cooling was also employed on the treatment site. No bleeding was observed during or after the procedure. Figure 3 shows the immediate postoperative view of the lesion. Vitamin E gel was applied on the lesion site immediately after excision to promote healing. The wound was left open without any sutures for healing by secondary intention. An anti-inflammatory analgesic was prescribed for 3 days along with application of vitamin E gel over the lesion site three times a day for 1 week. Patient was advised strictly to stop the lip-biting habit and not to consume any spicy or hot food for a few days and to rinse with normal saline three times a day for the following week.

The excised lesion was stored in $10 \%$ formalin and sent for biopsy for laboratory diagnosis (Fig. 4). The laboratory results confirmed the initial diagnosis of extravasation mucocele. The patient was instructed for follow-up visits on the third day to evaluate postoperative healing followed by a week and every month (Fig. 5). In the follow-up visits, the patient reported no discomfort or pain, and healing was satisfactory with no scarring.

\section{Histological Report}

The macroscopic findings of the excised tissue revealed soft tissue, brown in color, soft in consistency and measuring $0.4 \times 0.5 \times 0.2 \mathrm{~cm}$ in size. On microscopic examination, deeper connective tissue revealed mucin pooled and surrounded by muciphages and other inflammatory cell infiltrates (Fig. 6). The remaining connective tissue comprised collagen fibers and minor salivary gland. Surface epithelium was nonkeratinized stratified squamous.

\section{Discussion}

The laser diode, which was introduced in 1962, is manufactured from semiconductor crystals with a short wavelength $(800-980 \mathrm{~nm}$, and most recently, $1064 \mathrm{~nm}$ ). It works by transmitting photothermal energy to the cells it contacts, which causes an increase in temperature, vaporization, protein denaturation, and carbonization.

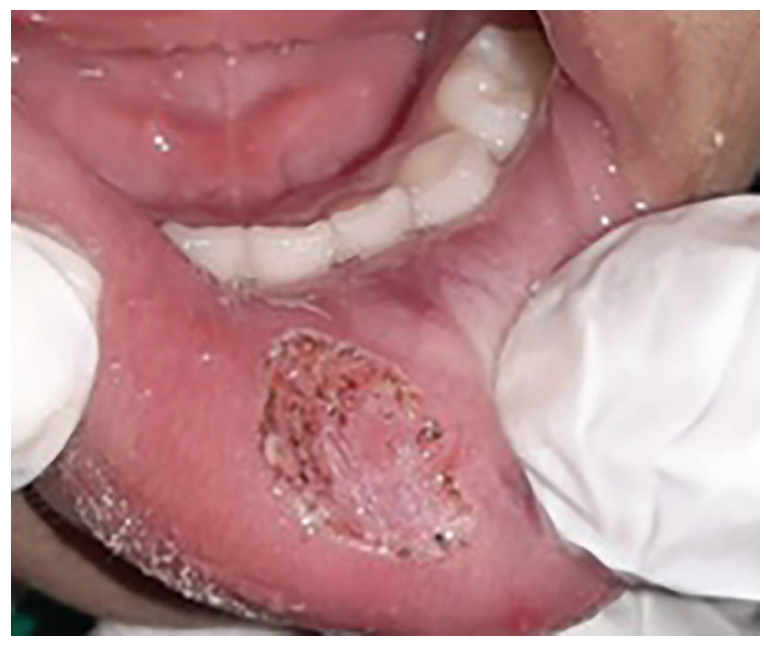

Fig. 3: Immediate postoperative view after excision

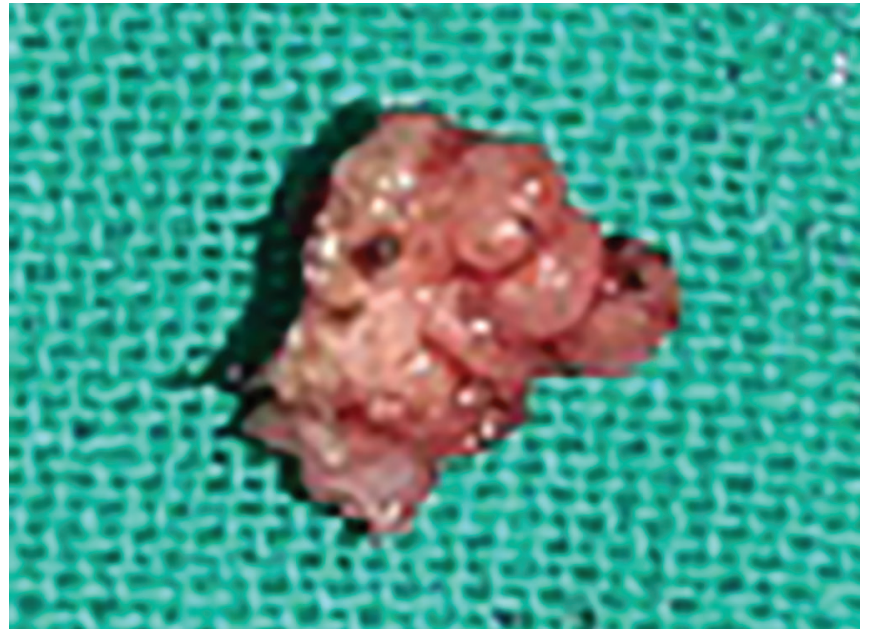

Fig. 4: Excised specimen (size $0.4 \times 0.5 \times 0.2 \mathrm{~cm}$ ) collected for histological examination

Due to the high affinity of the diode laser to certain protein molecules like hemoglobin and melanin, there is an elevation in the temperature thus promoting coagulation and hemostasis. ${ }^{4-6}$ In 2010, Pedron et al. reported that the laser diode is rapid, simple, and fast with minimal postoperative discomfort and scarring on one-month follow-ups. ${ }^{7}$

Mucocele is a self-limiting lesion of salivary glands with rapid onset and fluctuating size, commonly occurring in the oral cavity. The clinical features of mucocele are pathognomonic, and the following points like location, history of trauma, variations in size, rapid appearance, bluish color, and the consistency are crucial for its clinical diagnosis. ${ }^{8}$ The histopathologic findings of this lesion vary from acute inflammation with accumulation of mucus to the arrangement of lesions with lesser amounts of mucus and connective tissue fibrosis. The surface epithelium of the lesion may show hyperplastic parakeratinized stratified squamous tissue. The presence of spilled mucin surrounded by granulation tissue, small cystic spaces containing mucin, and sebaceous cells in the connective tissue are the histological features. ${ }^{3}$ Differential diagnosis of oral mucocele include lipoma, benign or malignant salivary gland neoplasms, oral hemangioma, venous varix, oral lymphangioma, irritational fibroma, gingival cyst of adults, oral lymphoepithelial cyst, soft tissue abscess, 

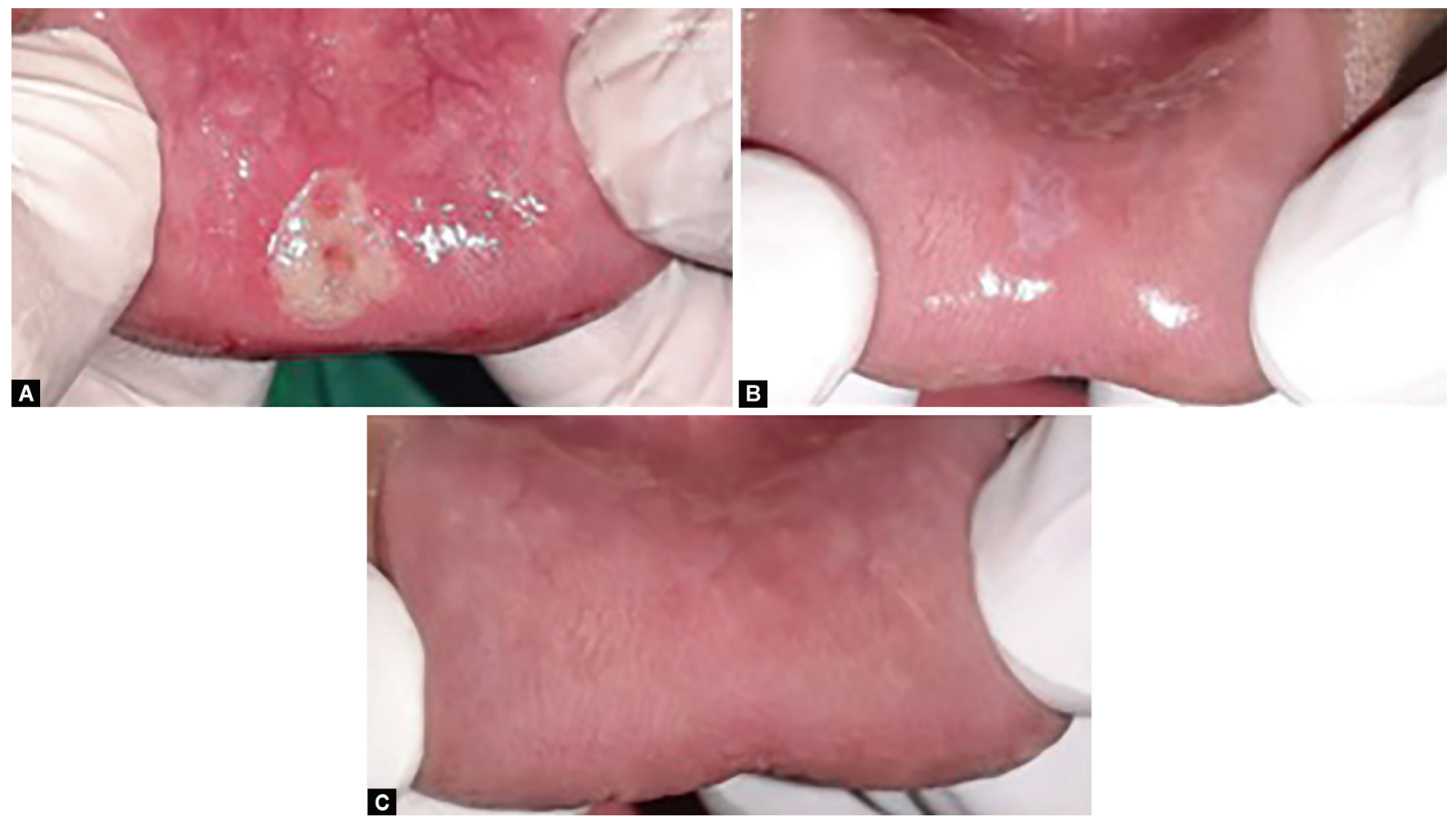

Figs 5A to C: Postoperative view of the healing lesion on (A) Day 3; (B) Day 10, and (C) After 45 days, respectively (top to bottom)

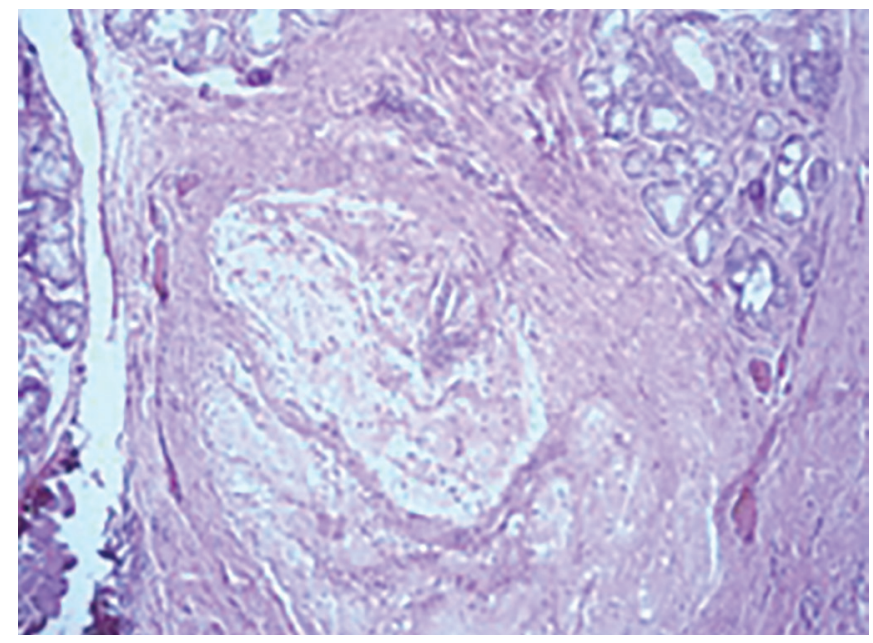

Fig. 6: Histological view showing central eosinophilic pooled area surrounded by foamy muciphages

pyogenic granuloma, cysticercosis, etc. Diagnosis is mainly based on clinical features like rapid occurrence, fluctuant swelling with soft consistency, bluish-to-pink color, specific location, recurrence, and associated history of trauma or oral habit. Occasionally, it may require routine radiographs, ultrasonography or advanced diagnostic methods - computed tomography and magnetic resonance imaging for better visualizing the form, position, and diameter, as well as for determination of the lesion origin.

\section{CONCLUSION}

Laser diode removal of oral mucocele is an alternative non-surgical procedure which can be performed in short span of time and achieve hemostasis that provides better results with minimum discomfort. Due to its variety of beneficial effects including bloodless operational field, good visualization, minimal swelling and scarring, it has good acceptance in pediatric patients.

\section{OrCID}

Siji Elizabeth @ https://orcid.org/0000-0001-8440-8625

\section{References}

1. Banerjee S, Bhowmick D, Banerjee A, Pramod J, Mukherjee A. Extravasation Type of Oral Mucocele-A Case Report. Journal of Orofacial \& Health Sciences. 2019;10(1):22-26. DOI: 10.5958/22293264.2019.00004.2.

2. Harrison JD. Salivary mucoceles. Oral Surgery, Oral Medicine, Oral Pathology 1975;39(2):268-278. DOI: 10.1016/0030-4220(75) 90228-5.

3. More CB, Bhavsar K, Varma S, et al. Oral mucocele: A clinical and histopathological study. J Oral Maxillofac Pathol 2014;18(Suppl 1): S72. DOI: 10.4103/0973-029X.141370.

4. Bagher SM, Sulimany AM, Kaplan M, et al. Treating mucocele in pediatric patients using a diode laser: Three case reports. Dent J 2018;6(2):13. DOI: 10.3390/dj6020013.

5. Delbem AC, Cunha RF, De Mello Vieira AE, et al. Treatment of mucus retention phenomena in children by the micro-marsupialization technique. Pediatr Dent 2000;22(2):155-158. PMID: 10769864.

6. Romanos G, Nentwig GH. Diode laser $(980 \mathrm{~nm}$ ) in oral and maxillofacial surgical procedures: Clinical observations based on clinical applications. J Clin Laser Med Surg 1999;17(5):193-197. DOI: 10.1089/clm.1999.17.193.

7. Pedron IG, Galletta VC, Azevedo LH, et al. Treatment of mucocele of the lower lip with diode laser in pediatric patients: Presentation of 2 clinical cases. Pediatr Dent. 2010;32(7):539-541. PMID: 21462769.

8. Nallasivam KU, Sudha BR. Oral mucocele: Review of literature and a case report. Journal of pharmacy \& bioallied sciences. 2015 Aug;7(Suppl 2):S731. DOI: 10.4103/0975-7406.163516. 